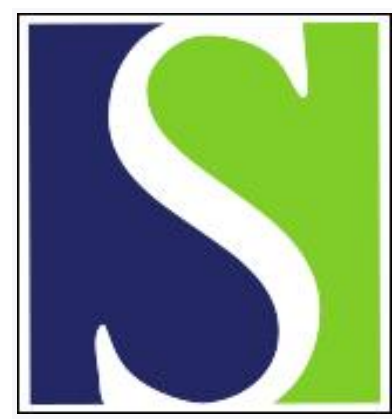

Scand J Work Environ Health 2012;38(1):27-37

https://doi.org/10.5271/sjweh.3169

Published online: 12 May 2011, Issue date: Jan 2012

Effectiveness of multidisciplinary primary prevention in decreasing the risk of work disability in a low-risk population by Saltychev M, Laimi K, El-Metwally A, Oksanen T, Pentti J, Virtanen M, Kivimäki M, Vahtera J

Affiliation: Department of Rehabilitation, Turku University Hospital, PO Box 52, Fl-20521 Turku, Finland. mikhail.saltychev@tyks.fi

The following articles refer to this text: 2013;39(1):57-65;

2015;41(5):491-503; 2016;42(4):273-279; 2019;45(6):651-660

Key terms: disability pension; early rehabilitation; low-risk population; multidisciplinary primary prevention; prevention; propensity score; rehabilitation; retirement; vocational rehabilitation; work disability

This article in PubMed: www.ncbi.nlm.nih.gov/pubmed/21573316 


\title{
Effectiveness of multidisciplinary primary prevention in decreasing the risk of work disability in a low-risk population
}

\author{
by Mikhail Saltychev MD, ${ }^{1}$ Katri Laimi PhD, ${ }^{2,3}$ Ashraf El-Metwally PhD, ${ }^{4,5}$ Tuula Oksanen PhD,6, 7 Jaana \\ Pentti BSc, ${ }^{6}$ Marianna Virtanen PhD, ${ }^{6}$ Mika Kivimäki PhD, , , 8, 9 Jussi Vahtera PhD ${ }^{3,6}$
}

\begin{abstract}
Saltychev M, Laimi K, El-Metwally A, Oksanen T, Pentti J, Virtanen M, Kivimäki M, Vahtera J. Effectiveness of multidisciplinary primary prevention in decreasing the risk of work disability in a low-risk population. Scand $J$ Work Environ Health. 2012;38(1):27-37. doi:10.5271/sjweh.3169
\end{abstract}

Objective The aim of this study was to evaluate the effectiveness of a 4-week primary prevention program (vocationally oriented multidisciplinary early rehabilitation or VOMR) in reducing the risk of long-term work disability among public sector employees at risk of deteriorating work capacity because of work-related strain.

Methods As a part of the prospective Finnish public sector study, a follow-up study was carried out among 1394 public sector employees who underwent VOMR and their 4146 propensity score-matched controls. Baseline characteristics of 41488 employees with full data on all 25 matching variables, measured from survey responses and national health registers, were used to calculate a propensity score for each employee to be granted rehabilitation. The cases were compared with the controls using Cox proportional hazard models as regards the risk of long-term work disability (sick leave $>90$ days or retirement on health grounds) after rehabilitation.

Results During a mean follow-up of 2.8 years [standard deviation (SD) 1.49, range 0.04-5.0], incident all-cause work disability was observed for $6.1 \%$ of the rehabilitants and $6.2 \%$ of the controls [hazard ratio (HR) 0.98 , $95 \%$ confidence interval (95\% CI) $0.76-1.25]$. The corresponding HR for the main causes of work disability stemming from musculoskeletal diseases and mental disorders were $0.86(95 \%$ CI $0.57-1.30)$ and 1.08 (95\% CI $0.67-1.74)$, respectively.

Conclusions VOMR was not associated with a lowered risk of long-term work disability compared to the controls. No support was obtained for the effectiveness of primary prevention for work disability in a low-risk cohort of employees.

Key terms disability pension; early rehabilitation; propensity score; rehabilitation; retirement; vocational rehabilitation.

Long-term work disability affects the economy of most Western countries even more than unemployment (1-4). Along with the rapid ageing and forthcoming shortage of the workforce, work disability creates a major problem and induces great interest in developing efficient ways to prevent early retirement on health grounds (5). To keep ageing employees in good health and assure their participation in worklife, preventive intervention needs to be adapted to a form that will improve the health, health behavior, and working conditions of workers and reduce work-related stress $(6,7)$.

Multidisciplinary medical and vocational rehabilitation programs are widely used to sustain participation in worklife $(8,9)$. Although there is some evidence of the effectiveness of multidisciplinary rehabilitation in general as regards the prevention of work disability $(8$, 10-17), there is still a lack of high-quality investigations on this subject (18-20). Vocationally oriented multi-

1 Department of Rehabilitation, Turku University Hospital, Turku, Finland.

2 Department of Physical and Rehabilitation Medicine, Turku University Hospital, Turku, Finland.

3 Department of Public Health, University of Turku and Turku University Hospital, Turku, Finland.

4 King Abdullah International Medical Research Center, King Saud bin Abdulaziz University for Health Sciences, Riyadh, Kingdom of Saudi Arabia.

5 Epidemiology Group, University of Aberdeen, Aberdeen, UK.

6 Finnish Institute of Occupational Health, Helsinki, Finland.

7 Department of Society, Human Development and Health, Harvard School of Public Health, Boston, MA, USA.

8 Department of Behavioral Sciences, University of Helsinki, Finland.

9 Department of Epidemiology and Public Health, University College London Medical School, London, UK.

Correspondence to: Mikhail Saltychev, Department of Rehabilitation, Turku University Hospital, PO Box 52, FI-20521 Turku, Finland. [E-mail: mikhail.saltychev@tyks.fi] 
disciplinary early rehabilitation (VOMR) was developed by the Social Insurance Institution of Finland (SII) more than 20 years ago on the basis of the assumption that deteriorating work capacity in physically or mentally stressful occupations could be predicted and prevented at an early stage. Unlike all other traditional forms of vocational or medical rehabilitation, VOMR targets lowrisk populations. The participants should be relatively healthy but "at risk" of developing deterioration of work capacity because of work-related strain. VOMR has become the largest rehabilitation program provided to working-aged Finns by SII. For example, in 2009 with expenses of about $€ 33$ million, VOMR represented $18 \%$ of all working-aged rehabilitation granted by SII (21).

Due to the unique character of VOMR's inclusion criteria (practically healthy people), the results of most earlier studies, conducted on traditional forms of medical or vocational rehabilitation amongst high-risk populations, are difficult to use in evaluating the program's effectiveness. Despite the fact that VOMR is the commonest type of rehabilitation targeting the Finnish working population, few studies on its effectiveness have been conducted thus far (22-28). Most of these studies did not have a natural control group, were conducted on a small number of participants, or were focused on secondary outcomes of VOMR $(22-25,27,28)$.

Some studies of VOMR have reported positive effects on subjective physical and mental strain at work (22), the severity of neck-shoulder and low-back pain $(22,23)$, and physical performance $(22,26,27)$, as well as improved ergonomics $(23-25,28)$, while others found no effects on these outcomes $(23,27)$. The effects of VOMR on the use of healthcare, subjective work ability, and the duration of sick leaves related to back pain have been found to be minor or insignificant $(22,23$, 26-28). In a recent study conducted by our research group, VOMR seemed to be effective in reducing the incidence of sickness absence and early retirement on health grounds for three subsequent years, but no longer than that, and the economic benefit was considered to be small when compared with the cost of the intervention (29). However, this registry-based study was not able to control for important behavioral and work-related risk factors, which left the study vulnerable to comparison biases. Furthermore, the effect of VOMR on diagnosisspecific, long-term work disability is still unknown.

Preventive intervention programs to improve the health and health behavior of workers and reduce workrelated stress are potentially important measures for keeping ageing employees in good health and assuring their participation in worklife $(6,7)$. The objective of this study was to evaluate the effectiveness of VOMR with respect to reducing the risk of long-term work disability and the risk of non-return to work attributed to medical conditions in general and separately due to musculoskeletal or mental disorders, the two most prevalent and significant causes of work disability in most European countries (30). To our knowledge, our study is the first attempt to investigate the effectiveness of primary prevention of work disability among a low-risk cohort of employees in a large prospective study using controls matched by their propensity score to minimize comparison bias.

\section{Methods}

\section{Study population}

This study was part of the Finnish public sector study, which is an ongoing prospective study among employees. The study, established in 1997-1998, comprises all 151618 employees with a $\geq 6$-month job contract in any year from 1991-2005 in 10 towns and 5 hospital districts in Finland. Questionnaire surveys were targeted at the 94494 employees who were at work in the years 1997-1998 (sub-cohort), 2000-2001, or 2004. Of these, 70376 participants responded at least once (response rate $74 \%$ ). All of the respondents have been followed with repeated surveys at 4-year intervals. In each survey, identifiable questionnaire data were gathered on psychosocial factors at work, individual factors, health, and health behaviors. With the use of the unique personal identification codes that are assigned to all citizens in Finland, these data were linked to national registers regarding special reimbursements for severe and chronic illnesses, prescriptions of medicines based on the anatomical therapeutic chemical defined daily dose (ATC-DDD) classification system, sickness absences, and disability pension with diagnoses, granted rehabilitation with diagnoses, work history, retirement, cancer morbidity, hospital admissions with diagnoses, and cause-specific mortality.

We included participants who responded to an identifiable survey either in 1997-1998 or 2000-2002. The first survey response was considered for those who answered both surveys (response rate $70 \%$ ), yielding a sample of 53416 employees ( $81 \%$ women). We excluded everyone who had been granted rehabilitation by SII before the baseline survey $(\mathrm{N}=4176)$ or had missing data on any of the matching variables $(\mathrm{N}=7752)$, the result being an eligible population of 1398 cases and 35946 non-cases of future VOMR. For each case, we selected up to 3 controls with the same propensity score as the case, the result being a total of 5540 participants (1394 rehabilitants and 4146 controls) for the statistical analyses (figure 1).

The Ethics Committee of the Finnish Institute of Occupational Health approved the study. 


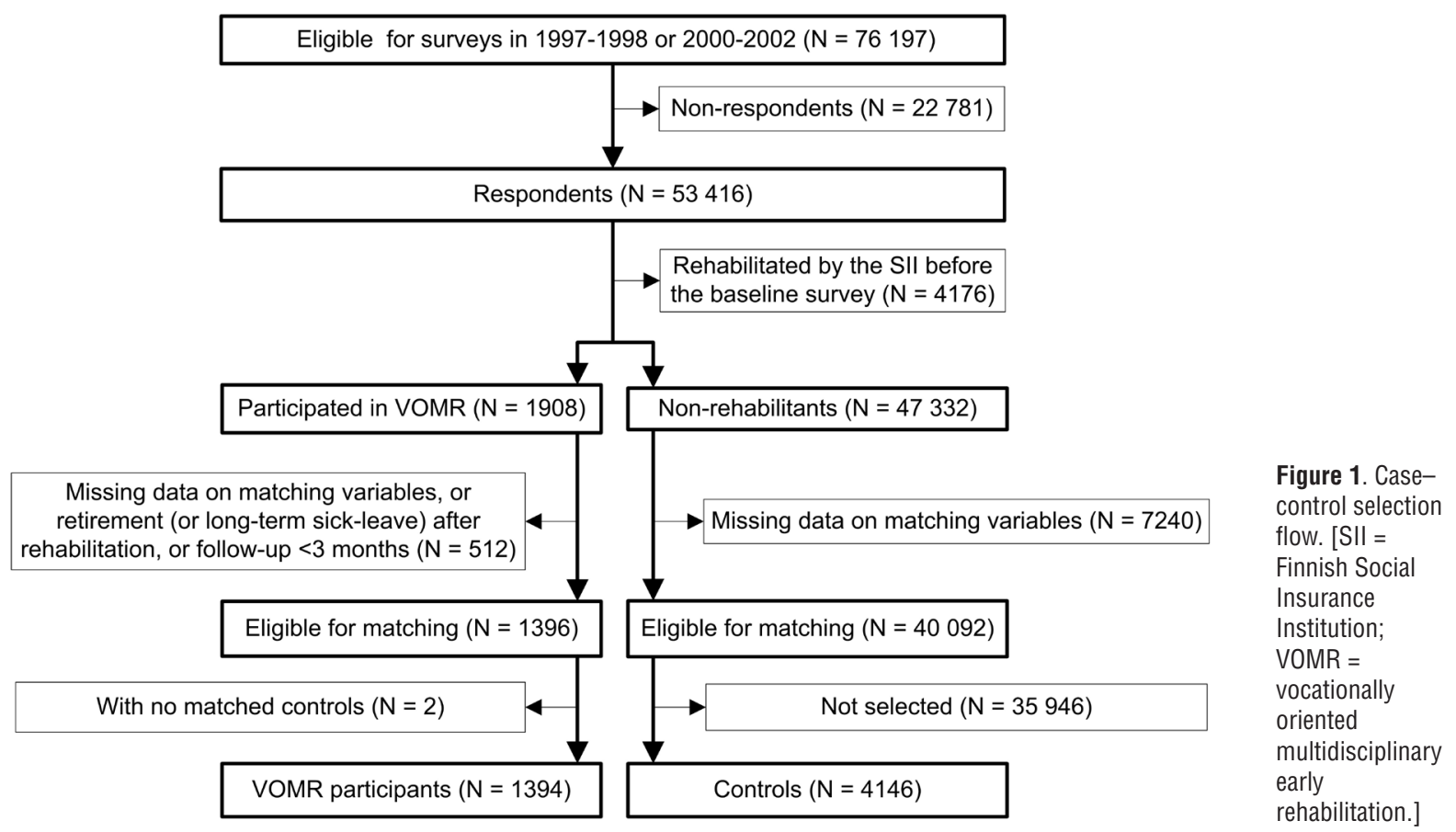

\section{Intervention}

In Finland, SII is the main provider of state-subsidized rehabilitation for people under the age of 65 years. It sponsors rehabilitation in independent rehabilitation centers to keep people fit for employment (31). VOMR is the commonest rehabilitation program sponsored by SII and accounts for $12.3 \%$ of the annual rehabilitation expenses of SII (21). In 2009, the median age of the employees participating in VOMR was 50 years (21).

VOMR is a group-based, multidisciplinary, early rehabilitation program that targets workplaces and occupations in which workers are subjected to considerable physical, mental, or social strain that may easily lead to health problems and a deterioration of working capacity. VOMR aims at the primary prevention of work disability. The participants generally have minor health problems only, as the VOMR selection criteria include, among others, an absence of recent long-term sick leave, a severe illness decreasing working capacity, or any indication of alcohol or drug abuse. The participants are selected by occupational physicians, and each group of rehabilitants usually has the same employer and/or profession. The final acceptance of selected employees is determined in social insurance offices around the country. The rejection rate is low, with only $13.1 \%$ of all applications for VOMR being rejected in 2009 (21).

The VOMR program contains three or four periods of in-patient, extensive, multi-modal, and multi-professional rehabilitation (total 15-21 days) implemented mostly as group-based ( $8-10$ persons) supervised activity (4-6 hours per day). The multi-professional team consists of a physician, physiotherapist, psychologist, social worker, and a vocational rehabilitation specialist. In addition, a nurse, occupational therapist, occupational physiotherapist, and a nutritionist are often involved. The modalities include physiotherapy and physical and psychological education. All activities target improvement of physical and mental health status of the participants, enhancing their stress-management and encouraging a healthy lifestyle (eg, improving dietary habits and leisure-time physical activity and reducing or quitting smoking and alcohol consumption). The concept of physical training includes individual assessment of the participants, and the plan for exercising at home, during workday breaks, and the in-patient period of the program. It also includes ergonomic education and exercises performed in groups. Problems at the worksites, such as work-related strain and ways to manage it, are discussed in group-based sessions with a psychologist, social worker, and a physician. The program includes a one-day participation of the representatives from the worksite (usually supervisor and occupational physician) in joint-group sessions. Sometimes adjustments are made to the physical work environment.

Although VOMR is implemented in different independent rehabilitation facilities, the SII strictly defines the inclusion criteria, the structure of the program, the multi-professional team composition, the modalities, and the assessment tests. The program follows this 
pre-determined plan but the content of the group-based sessions may differ slightly, based on the occupational characteristics of the participants in the group. Between the in-patient periods, the participants are expected to follow an individual exercise plan at home, which usually consists of self-reliant physical activities and psychological exercises

The participants do not work during in-patient periods, and the entire program is free of charge. The participants receive a so-called "rehabilitation compensation" paid by the SII, which is about $75 \%$ of the participant's usual salary (minimum €22 per workday). Employers are not financially compensated for hiring temporary agency workers or substitutes.

\section{Outcome - long-term work disability}

The outcome measure was documented as long-term work disability, defined as either sick leave $>90$ days or disability retirement, whichever came first. We used 90 days as a cut-off point for sick leave because, from 1997 on, diagnoses have been available for these very long absences. The outcome was quantified using data obtained from the SII sickness absence register and the pension register of the Finnish Centre for Pensions. These national registers reliably cover all reimbursed sickness absences and retirements in that all Finnish residents aged 16-67 years are eligible for daily allowances due to medically certified sickness absence and all gainful employment is insured in some pension scheme and accrues a pension. Work disability was analyzed, firstly, as being caused by any disease and, secondly, as being caused by musculoskeletal or mental disorders.

\section{Variables used in propensity score matching}

In addition to the survey year, 25 variables shown in these data to be associated with the probability of VOMR in the future were selected for the propensity score matching (32). The demographic characteristics included age, gender, occupational grade, type of employer, region, education, and marital status. Information on these variables was extracted from the employers' records, except for education and marital status which were taken from the survey data. Survey responses were used to determine the work characteristics, such as work schedules (shift work), intention to leave work, job insecurity, job control, and life stress. Data on the type and length of the job contract were derived from the employers' registers. Health risk behaviors were assessed from the survey responses and included current smoking, excessive alcohol consumption, obesity, and low physical activity. Health indicators were taken from the survey responses and included psychological distress, anxiety, and self-rated health. Data on baseline physical health were obtained from the drug reimbursement register while information on the use of prescribed painkillers and antidepressants came from the drug prescription register.

\section{Definitions}

The participants were categorized into three age groups $(<41,41-50$, and $>50$ years). Occupational grade was categorized according to the International Standard Classification of Occupations (ISCO) into managers and professionals (ISCO major groups 1-2), technicians and associate professionals (group 3), clerks (group 4), service workers (group 5), and manual workers (groups 6-9). The type of employer was categorized as municipality or hospital district and the residential region as Southern, Central, or Northern Finland. Marital status was defined as married or cohabiting versus single, divorced, or widowed. Educational level was dichotomized as high school versus no high school.

The type of job contract was dichotomized as permanent or temporary and the length of the contract was categorized into three groups $(<1,1-9,>9$ years). Shift work was determined from the following direct question: "Do you work regular day shifts?" (yes/no). An intention to leave work identified those who would, if possible, switch to another job or give up work from those who would continue to work in the same job. Job insecurity was assessed by two questions, which estimated the threat of long-term unemployment or dismissal (from 1=very little to $5=$ =very much). A mean score was computed and divided into tertiles. Job control was measured by 9 items derived from the job content questionnaire. A mean score was computed and divided into tertiles to indicate low, intermediate, and high job control. Life stress was measured by the occurrence of severe financial difficulties during the baseline year (yes/no).

Current smoking was defined as no or yes. The participants reported their average weekly consumption of beer, wine, and spirits in portions. The portions were converted into grams of pure alcohol, and $>210 \mathrm{~g}$ of pure alcohol per week was considered a cut-off for excess alcohol consumption (no/yes). Derived from selfreported weight and height, the body mass index (BMI) was calculated and dichotomized to indicate obesity (BMI $\geq 30$ ). The participants assessed the quantity of their physical activity as equivalent to walking, brisk walking, jogging, or running. Low physical activity was defined as $\geq 2$ metabolic equivalent task (MET) hours per day (no/yes).

Psychological distress (no/yes) was evaluated from the 12-item version of the general health questionnaire (GHQ), using 3/4 as the cut-off point. Anxiety was assessed with the 6-item trait anxiety inventory. A mean score was computed and divided into tertiles to indicate low, intermediate, and high anxiety. Self-rated 
health status was classified as sub-optimal (average or worse) or optimal (good or very good health). Previous rehabilitation was defined as rehabilitation provided by SII within the 3 years immediately prior to the baseline survey year. Baseline physical health included the presence of a chronic disease (no/yes), as indicated by special reimbursement for the medical treatment of hypertension, cardiac failure, ischemic heart disease, diabetes, asthma or other chronic obstructive lung disease, and rheumatoid arthritis derived from the drug reimbursement register. From the drug prescription register, we determined the use of prescribed painkillers and antidepressants. During the survey year, the participants who purchased more than $30 \mathrm{DDD}$ of analgesics (ATC classification code N02 and M01A) were coded as painkiller users; and those who purchased more than 30 DDD of antidepressants (ATC code N06A) were coded as antidepressant users (table 1).

\section{Statistical analysis}

In recent years, matching adjustment procedures based on a propensity score have become increasingly popular (33-35). For each participant in VOMR, propensity-based matching (a quasi-experimental "correction strategy") was used to select 1-3 controls who had the same probability of being selected to VOMR as the case (propensity score differed by $<0.01$, the most accurate selected first). The propensity score was computed using logistic regression with the dependent variable being rehabilitated (yes/ no), and using the 25 covariates and their interactions with gender and age-group as the predictor variables (in all, 121 terms included in the model). To examine the extent to which the matching was successful, we tested the differences in each independent matching variable between the cases and controls using the Chi-square test.

Follow-up for long-term work disability began immediately after the rehabilitation and ended with a long-term sickness absence or disability pension, official retirement pension (old-age pension), death, or 31 December 2005, whichever came first. Cox proportional hazard models were used to study the risk of work disability between the rehabilitants and controls. The results were reported as hazard ratios (HR) and their $95 \%$ confidence intervals $(95 \% \mathrm{CI})$.

All of the statistical analyses were performed using SAS version 9.2 (SAS Institute Inc, Cary, NC, USA).

\section{Results}

The occupational status of the rehabilitants, according to the International Standard Classification of Occupations (ISCO), varied widely between manual workers and managers (table 1). Most of the rehabilitants were permanently employed (92\%). Only every sixth experienced high job insecurity, and every fifth was intending to give up the job. Most of the rehabilitants were healthy, reported good self-rated health $(80 \%)$, had healthy habits, and did not use prescribed painkillers or antidepressants. They also reported low levels of anxiety and psychological distress (table 1). In support of the success of matching by the propensity scores, in essence, we observed no differences between the rehabilitants and their controls as regards the individual variables used in the calculation of the propensity score, except for selfreported psychological distress, and the participant's age (table 1). The health-related characteristics of the rehabilitants and the controls were similar also at the time the rehabilitation started (table 2).

During the mean follow up of 2.8 years [standard deviation (SD) 1.49, range 0.04-5.0], incident longterm work disability due to any disease was observed for $85(6.1 \%)$ rehabilitants and 257 (6.2\%) controls. The Kaplan-Meir curves, showing the probability of work disability for cases and controls, were practically identical over the whole exposure window (figure 2).

The HR for incident work disability due to any disease was 0.98 (95\% CI $0.76-1.25)$ between all of the rehabilitants and controls: 0.96 (95\% CI $0.74-1.26)$ for the women and $1.10(95 \%$ CI $0.55-2.20)$ for the men. For work disability due to musculoskeletal causes and mental disorders, the corresponding HR were $0.86(95 \%$ CI $0.57-1.30)$ and 1.08 (95\% CI 0.67-1.74), respectively (table 3 ).

The risk of non-return to work within a 1-year time window could be examined for 61 out of 85 rehabilitants and 177 of the 257 controls who received a work disability benefit. Although a slightly higher proportion of the rehabilitants than the controls returned to work, the risk of non-return did not significantly differ between the cases and the controls in relation to all-cause or causespecific work disability (table 3 ).

\section{Discussion}

In this prospective cohort study of 1394 public sector employees who underwent VOMR, no difference in allcause or cause-specific work disability emerged after the rehabilitation in comparison with the 4146 propensity score-matched controls. The rehabilitation was a primary prevention program to support work capacity in physically or mentally stressful occupations at an early stage, before any actual deterioration of work capacity due to an illness had developed.

Some previous studies have reported positive effects of multidisciplinary rehabilitation on the risk of work 
Table 1. Distribution of the variables used for the propensity score matching of the rehabilitants and controls. [ISCO=International Standard Classification of Occupations; BMI=body mass index.]

\begin{tabular}{|c|c|c|c|c|c|c|c|c|c|}
\hline \multirow{2}{*}{$\begin{array}{l}\text { Covariates used in the } \\
\text { propensity score matching }\end{array}$} & \multicolumn{4}{|c|}{ Rehabilitants ( $N=1394)$} & \multicolumn{4}{|c|}{ Control group ( $N=4146)$} & \multirow{2}{*}{$\begin{array}{l}\text { Chi2-tes } \\
\text { P-value }\end{array}$} \\
\hline & $\mathrm{N}$ & $\%$ & Mean & Range & $\mathrm{N}$ & $\%$ & Mean & Range & \\
\hline Propensity score & & & 0.082 & $0.002-0.297$ & & & 0.081 & $0.002-0.295$ & \\
\hline Gender ${ }^{a}$ & & & & & & & & & 0.685 \\
\hline Women & 1214 & 87 & & & 3593 & 87 & & & \\
\hline Men & 180 & 13 & & & 553 & 13 & & & \\
\hline Age-group (years) a & & & & & & & & & 0.001 \\
\hline$\leq 40$ & 315 & 23 & & & 1036 & 25 & & & \\
\hline $41-50$ & 850 & 61 & & & 2584 & 62 & & & \\
\hline$\geq 51$ & 229 & 16 & & & 526 & 13 & & & \\
\hline ISCO grade a & & & & & & & & & 0.690 \\
\hline 1-2 (managers) & 506 & 36 & & & 1466 & 35 & & & \\
\hline 3 & 365 & 26 & & & 1098 & 26 & & & \\
\hline 4 & 59 & 4 & & & 215 & 5 & & & \\
\hline 5 & 306 & 22 & & & 904 & 22 & & & \\
\hline 6-9 (manual) & 158 & 11 & & & 463 & 11 & & & \\
\hline Type of employer a & & & & & & & & & 0.766 \\
\hline Municipality & 870 & 62 & & & 2569 & 62 & & & \\
\hline Hospital district & 524 & 38 & & & 1577 & 38 & & & \\
\hline Residential region a & & & & & & & & & 0.681 \\
\hline Southern Finland & 799 & 57 & & & 2331 & 56 & & & \\
\hline Central Finland & 418 & 30 & & & 1295 & 31 & & & \\
\hline Northern Finland & 177 & 13 & & & 520 & 13 & & & \\
\hline Marital status ${ }^{b}$ & & & & & & & & & 0.375 \\
\hline Married/cohabiting & 1081 & 78 & & & 3262 & 79 & & & \\
\hline Single & 313 & 22 & & & 884 & 21 & & & \\
\hline High school education ${ }^{\mathrm{b}}$ & & & & & & & & & 0.401 \\
\hline No & 636 & 46 & & & 1838 & 44 & & & \\
\hline Yes & 758 & 54 & & & 2308 & 56 & & & \\
\hline Job contract ${ }^{a}$ & & & & & & & & & 0.315 \\
\hline Permanent & 1286 & 92 & & & 3789 & 91 & & & \\
\hline Fixed-term & 108 & 8 & & & 357 & 9 & & & \\
\hline Length of job contract ${ }^{a}$ (years) & & & & & & & & & 0.169 \\
\hline$\geq 10 r$ & 227 & 16 & & & 684 & 17 & & & \\
\hline $1-9$ & 1007 & 72 & & & 2908 & 70 & & & \\
\hline$<1$ & 160 & 11 & & & 554 & 13 & & & \\
\hline Shift work ${ }^{b}$ & & & & & & & & & 0.442 \\
\hline No & 894 & 64 & & & 2706 & 65 & & & \\
\hline Yes & 500 & 36 & & & 1440 & 35 & & & \\
\hline Intention to leave work ${ }^{b}$ & & & & & & & & & 0.447 \\
\hline Continue the job & 727 & 52 & & & 2114 & 51 & & & \\
\hline Switch jobs & 402 & 29 & & & 1270 & 31 & & & \\
\hline Give up the job & 265 & 19 & & & 762 & 18 & & & \\
\hline Job insecurity b & & & & & & & & & 0.832 \\
\hline Low & 589 & 42 & & & 1782 & 43 & & & \\
\hline Intermediate & 577 & 41 & & & 1678 & 40 & & & \\
\hline High & 228 & 16 & & & 686 & 17 & & & \\
\hline Job control b & & & & & & & & & 0.632 \\
\hline Low & 340 & 24 & & & 1006 & 24 & & & \\
\hline Intermediate & 480 & 34 & & & 1377 & 33 & & & \\
\hline High & 574 & 41 & & & 1763 & 43 & & & \\
\hline Obesity ${ }^{\mathrm{b}}\left(\mathrm{BMl}>30 \mathrm{~kg} / \mathrm{m}^{2}\right)$ & & & & & & & & & 0.853 \\
\hline No & 1269 & 91 & & & 3781 & 91 & & & \\
\hline Yes & 125 & 9 & & & 365 & 9 & & & \\
\hline Smoking b & & & & & & & & & 0.654 \\
\hline No & 1207 & 87 & & & 3570 & 86 & & & \\
\hline Yes & 187 & 13 & & & 576 & 14 & & & \\
\hline Alcohol consumption ${ }^{\mathrm{b}}$ (g/week) & & & & & & & & & 0.867 \\
\hline $0-210 \mathrm{~g}$ & 1295 & 93 & & & 3846 & 93 & & & \\
\hline$>210 \mathrm{~g}$ & 99 & 7 & & & 300 & 7 & & & \\
\hline
\end{tabular}


Table 1. (continued)

\begin{tabular}{|c|c|c|c|c|c|c|c|c|c|}
\hline \multirow{2}{*}{$\begin{array}{l}\text { Covariates used in the } \\
\text { propensity score matching }\end{array}$} & \multicolumn{4}{|c|}{ Rehabilitants ( $N=1394)$} & \multicolumn{4}{|c|}{ Control group $(\mathrm{N}=4146)$} & \multirow{2}{*}{$\begin{array}{l}\text { Chi 2-tes } \\
\text { P-value }\end{array}$} \\
\hline & N & $\%$ & Mean & Range & $\mathrm{N}$ & $\%$ & Mean & Range & \\
\hline Physical inactivity ${ }^{b}$ & & & & & & & & & 0.449 \\
\hline No & 1110 & 80 & & & 3340 & 81 & & & \\
\hline Yes & 284 & 20 & & & 806 & 19 & & & \\
\hline Sickness absence c (days/3 years) & & & & & & & & & 0.260 \\
\hline No & 939 & 67 & & & 2886 & 70 & & & \\
\hline $1-59$ & 359 & 26 & & & 1007 & 24 & & & \\
\hline$\geq 60$ & 96 & 7 & & & 253 & 6 & & & \\
\hline Chronic medical conditions ${ }^{d}$ & & & & & & & & & 0.586 \\
\hline No & 1291 & 93 & & & 3821 & 92 & & & \\
\hline Yes & 103 & 7 & & & 325 & 8 & & & \\
\hline Use of antidepressants ${ }^{e}$ & & & & & & & & & 0.487 \\
\hline No & 1256 & 95 & & & 3720 & 95 & & & \\
\hline Yes & 68 & 5 & & & 182 & 5 & & & \\
\hline Use of painkillers ${ }^{e}$ & & & & & & & & & 0.416 \\
\hline No & 1010 & 76 & & & 3019 & 77 & & & \\
\hline Yes & 314 & 24 & & & 883 & 23 & & & \\
\hline Anxiety ${ }^{b}$ & & & & & & & & & 0.212 \\
\hline Low & 346 & 25 & & & 1066 & 26 & & & \\
\hline Intermediate & 558 & 40 & & & 1729 & 42 & & & \\
\hline High & 490 & 35 & & & 1351 & 33 & & & \\
\hline Poor self-rated health ${ }^{b}$ & & & & & & & & & 0.106 \\
\hline No & 1085 & 78 & & & 3311 & 80 & & & \\
\hline Yes & 309 & 22 & & & 835 & 20 & & & \\
\hline Psychological distress ${ }^{b}$ & & & & & & & & & 0.032 \\
\hline No & 1022 & 73 & & & 3158 & 76 & & & \\
\hline Yes & 372 & 27 & & & 988 & 24 & & & \\
\hline
\end{tabular}

a Data obtained from employer's records.

${ }^{\mathrm{b}}$ Data obtained from survey.

c Data obtained from the sickness absence register of the Finnish Social Insurance Institution (SII).

d Data obtained from the drug reimbursement register of the SII.

${ }^{\mathrm{e}}$ Data obtained from the drug prescription register of the SII.

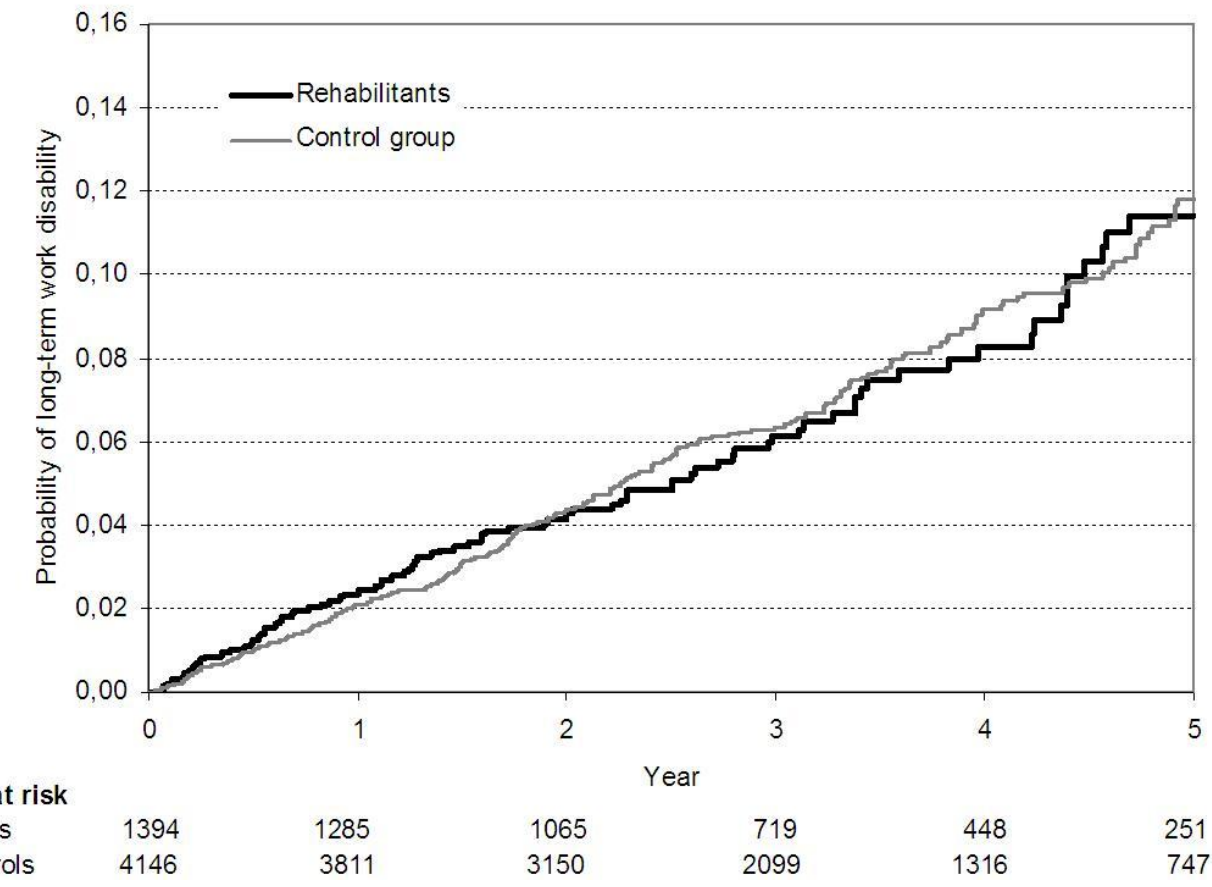

Figure 2. Incidence of long-term work disability (long-term sickleave or disability retirement) during the follow-up. 
disability, but these studies, rather than focusing on primary prevention, evaluated the rehabilitation of persons whose work capacity had already deteriorated and/or had substantial health problems $(8,10-17)$. Few studies have evaluated the effectiveness of VOMR, a unique form of rehabilitation targeting employees at risk but still relatively healthy. These studies were mostly uncontrolled, had small study populations, and focused on secondary non-vocational outcomes of VOMR. They reported inconsistent evidence of the effects of VOMR

Table 2. Register-based distribution of the health-related variables amongst the rehabilitants and controls at the beginning of the rehabilitation.

\begin{tabular}{|c|c|c|c|c|c|}
\hline \multirow[t]{2}{*}{ Health indicators } & \multicolumn{2}{|c|}{$\begin{array}{l}\text { Rehabilitants } \\
\quad(N=1394)\end{array}$} & \multicolumn{2}{|c|}{$\begin{array}{l}\text { Controls } \\
(\mathrm{N}=4146)\end{array}$} & \multirow{2}{*}{$\begin{array}{c}\text { Chi } \\
\text { 2-test } \\
\text { P-value }\end{array}$} \\
\hline & $\mathrm{N}$ & $\%$ & $\mathrm{~N}$ & $\%$ & \\
\hline $\begin{array}{l}\text { Sickness absence } \\
\text { (days } / 1 \text { year) }\end{array}$ & & & & & 0.905 \\
\hline 0 & 1176 & 84 & 3479 & 84 & \\
\hline $1-29$ & 123 & 9 & 371 & 9 & \\
\hline$\geq 30$ & 95 & 7 & 296 & 7 & \\
\hline $\begin{array}{l}\text { Chronic medical } \\
\text { conditions }\end{array}$ & & & & & 0.757 \\
\hline No & 1245 & 89 & 3715 & 90 & \\
\hline Yes & 149 & 11 & 431 & 10 & \\
\hline Use of antidepressants & & & & & 0.203 \\
\hline No & 1273 & 96 & 3719 & 95 & \\
\hline Yes & 51 & 4 & 183 & 5 & \\
\hline Use of painkillers & & & & & 0.172 \\
\hline No & 1137 & 86 & 3408 & 87 & \\
\hline Yes & 187 & 14 & 494 & 13 & \\
\hline
\end{tabular}

on subjective physical and mental strain at work, severity of neck-shoulder and low-back pain, physical performance, subjective work ability, improvement in ergonomics, and the use of healthcare services (22-28). Although VOMR has been widely used since the early 1980s, we could not find any studies that primarily focused on evaluating the effectiveness of VOMR on attaining its main goal - decreasing the risk of long-term work disability - except for a recently published investigation by our study group (29). This registry-based study of 2236 municipal employees and 8944 matched controls found relatively small and short-term effects of VOMR on the prevention of work disability, the results suggesting that these direct health benefits may not fully compensate for the costs of the intervention (29). However, because all of the data were derived from registers, the study was unable to control for important behavioral and work-related risk factors.

A valid epidemiologic evaluation of the outcome of rehabilitation is difficult. As persons receiving rehabilitation are, by definition, disadvantaged in one way or another, a random selection of non-recipients is likely to result in a group of persons not disadvantaged to the same extent as the recipients. A direct comparison of these two groups would thus be biased in favor of the non-recipients because they have a "head start" over the recipients. A study in the United States on the granting of service found that most of the granting process remained unexplained and therefore indicated that the process was largely governed by subjective assessments by individual case workers, favoring, for

Table 3. Incidence of cause-specific work disability (sick leave $>90$ days or disability retirement) and the risk of non-return to work within 1 year of the beginning of the work disability. [HR=hazard ratio; $95 \% \mathrm{Cl}=95 \%$ confidence interval.]

\begin{tabular}{|c|c|c|c|c|c|c|}
\hline & \multicolumn{2}{|c|}{$\begin{array}{l}\text { Participants on long-term } \\
\text { sick leave or retired }\end{array}$} & \multicolumn{2}{|c|}{$\begin{array}{l}\text { Participants not returning } \\
\text { to work }\end{array}$} & \multirow[t]{2}{*}{$\mathrm{HR}$} & \multirow[t]{2}{*}{$95 \% \mathrm{Cl}$} \\
\hline & $\mathrm{N}$ & $\%$ & $\mathrm{~N}$ & $\%$ & & \\
\hline \multicolumn{7}{|l|}{ Incidence of work disability } \\
\hline \multicolumn{7}{|c|}{ Work disability / any disease } \\
\hline Rehabilitants $(\mathrm{N}=1394)$ & 85 & 6 & . & . & 0.98 & \multirow{2}{*}{$\begin{array}{r}0.76-1.25 \\
\text { reference }\end{array}$} \\
\hline Controls $(\mathrm{N}=4146)$ & 257 & 6 & . & . & 1.00 & \\
\hline \multicolumn{7}{|c|}{ Work disability / mental disease } \\
\hline Rehabilitants & 23 & 27 & . & . & 1.08 & \multirow{2}{*}{$\begin{array}{r}0.67-1.74 \\
\text { reference }\end{array}$} \\
\hline Controls & 63 & 25 & . & . & 1.00 & \\
\hline \multicolumn{7}{|c|}{ Work disability / musculoskeletal disease } \\
\hline Rehabilitants & 29 & 34 & . & . & 0.86 & \multirow{2}{*}{$\begin{array}{r}0.57-1.30 \\
\text { reference }\end{array}$} \\
\hline Controls & 100 & 39 & . & . & 1.00 & \\
\hline \multicolumn{7}{|l|}{ Risk of non-return to work } \\
\hline \multicolumn{7}{|c|}{ Work disability / any disease } \\
\hline Rehabilitants ( $\mathrm{N}=61$ ) & . & . & 16 & 26 & 0.82 & \multirow{2}{*}{$\begin{array}{r}0.51-1.32 \\
\text { reference }\end{array}$} \\
\hline Controls ( $N=177$ ) & . & . & 57 & 32 & 1.00 & \\
\hline \multicolumn{7}{|c|}{ Work disability / mental disease } \\
\hline Rehabilitants $(\mathrm{N}=17)$ & . & . & 3 & 18 & 0.60 & \multirow{2}{*}{$\begin{array}{r}0.19-1.87 \\
\text { reference }\end{array}$} \\
\hline Controls $(\mathrm{N}=41)$ & . & . & 12 & 29 & 1.00 & \\
\hline \multicolumn{7}{|c|}{ Work disability / musculoskeletal disease } \\
\hline Rehabilitants $(\mathrm{N}=20)$ & . & . & 6 & 30 & 0.72 & \multirow{2}{*}{$\begin{array}{l}0.35-1.48 \\
\text { reference }\end{array}$} \\
\hline Controls $(\mathrm{N}=67)$ & . & . & $\begin{array}{r}0 \\
28\end{array}$ & 42 & 1.00 & \\
\hline
\end{tabular}


example, people with the most potential gain from the service (optimizing the economic efficiency) or people most likely to succeed ("creaming") (36). In this study, we used propensity-based matching to handle treatment selection bias. This method is used to select control patients who are similar to patients receiving treatment with respect to their propensity scores and other covariates, while discarding unmatched persons and thereby matching on many confounders simultaneously (37). Although matched analyses may analyze a nonrepresentative sample of persons receiving treatment or rehabilitation, they can provide a more valid estimate of treatment effect because they compare rehabilitants only with those non-rehabilitants who have similar observed characteristics prior to the rehabilitation and are thus also potential candidates for the treatment.

Although the employees receiving VOMR were matched to the closest controls, all with a $<0.01$ difference in the propensity score, the effects of hidden bias in an observational study such as ours cannot be ruled out. However, in case of major treatment selection bias one would expect to see a strong benefit from rehabilitation, a likely consequence of "cherry picking" or "creaming". In our study, the rehabilitants were selected from a lowrisk population in relation to the outcome, and their risk of work disability was similar to that of the non-treated controls. These observations suggest that treatment selection bias is an unlikely explanation for our findings.

It remains unclear why VOMR seems to be inefficient in reducing the risk of long-term work disability. One possibility is that the basic assumption of primary prevention of the deterioration of work disability by means of early rehabilitation is non-optimal, or that the selection of participants into VOMR in terms of their risk of work disability fails. Indeed, in our cohort, VOMR was more often granted to employees with few known risk factors (32). Not only was there a lack of association between the most important modifiable risks (38) and future rehabilitation, but also a lack of smoking, physical inactivity, and work stress increased future chances of being granted rehabilitation to sustain worklife participation. Thus it is possible that the VOMR selection process does not catch relevant indicators of the need for primary prevention in the prediction of which healthy employee is going to withstand all strain at work and remain healthy and which is going to develop a chronic medical condition and deteriorated work capacity. Another reason for not finding evidence of effectiveness of VOMR in our study could be non-adherence (ie, the participants may not follow the individual plans during out-patient periods).

In Western societies, $4-12 \%$ of the working-age population receive disability pension benefits annually $(39,40)$. Musculoskeletal and mental disorders account for the most common disease groups resulting in ill- health retirement (41-44). Thus, there is a great need for effective measures to reduce the economic burden of early retirement on societies, employers, and employees. One such measure, specifically developed for this purpose in Finland, is VOMR. Unfortunately, our study suggests that the effectiveness of VOMR in reducing the burden of long-term work disability, when implemented as represented in this study, is questionable. Our speculation is that the effectiveness of the program might be enhanced by more precise criteria for participant selection and modifying the content of the program towards a more individual and practical approach to address both participant and worksite needs.

\section{Strengths and weaknesses of the study}

The strengths of this prospective study are its large study population and minimization of treatment selection bias through the use of propensity score matching for creating a similar control group based on wide-ranging data collected from surveys and national registers. However, the study population consisted only of full-time public sector employees, and this feature may have reduced the generalizability of the findings to other branches of industry. Possibly because of the small numbers of cases, findings regarding non-return to work were statistically insignificant. Our study assessed only the main vocational outcome of VOMR, and hence it is possible that this rehabilitation type has other beneficial effects on the rehabilitant's individual characteristics, such as health-risk behavior, work satisfaction, anxiety level, self-rated health, or pain intensity.

\section{Concluding remarks}

Our results imply that primary prevention of long-term work disability may not be achieved with VOMR. We encourage Finnish policy-makers to take these results into consideration when allocating limited rehabilitation funds. Future research is needed to uncover the underlying causes of the ineffectiveness of this costly early intervention program and identify more effective preventive measures to sustain the worklife participation of older employees in Western welfare states with rapidly ageing workforces.

\section{Acknowledgements}

The Finnish Public Sector Study is supported by the Academy of Finland (projects 124271, 124322, and $132944)$ and the participating organizations. The authors declare no competing interests. 


\section{References}

1. Organisation for Economic Co-operation and Development (OECD). Sickness, disability and work: breaking the barriers: Norway, Poland and Switzerland. Vol. 1. Paris: OECD 2006. doi:10.1787/9789264026322-en.

2. Organisation for Economic Co-operation and Development (OECD). Sickness, disability and work: breaking the barriers: Australia, Luxembourg, Spain and the United Kingdom. Vol. 2. Paris: OECD 2007. doi:10.1787/9789264038165-en.

3. Organisation for Economic Co-operation and Development (OECD). Sickness, disability and work: breaking the barriers: Denmark, Finland, Ireland and the Netherlands. Vol. 3. Paris: OECD 2008. doi :10.1787/9789264049826-en.

4. Whyte J. Rehabilitation effectiveness: the state of the science and a hope for the future. Am J Phys Med Rehabil. 2007;86:835-7. doi:10.1097/PHM.0b013e3181570b74.

5. Christensen K, Doblhammer G, Rau R, Vaupel JW. Ageing populations: the challenges ahead. Lancet. 2009;374:1196208. doi:10.1016/S0140-6736(09)61460-4.

6. Burdorf A. Is early retirement good for your health? BMJ. 2010;341:c6089. doi: 10.1136/bmj.c6089.

7. Westerlund H, Vahtera J, Ferrie JE, Singh-Manoux A, Pentti J, Melchior M, et al. Effect of retirement on major chronic conditions and fatigue: French GAZEL occupational cohort study. BMJ. 2010;341:c6149. doi: 10.1136/bmj.c6149.

8. Norlund A, Ropponen A, Alexanderson K. Multidisciplinary interventions: review of studies of return to work after rehabilitation for low back pain. J Rehabil Med. 2009;41:11521. doi:10.2340/16501977-0297.

9. van Geen JW, Edelaar MJ, Janssen M, van Eijk JT. The longterm effect of multidisciplinary back training: a systematic review. Spine (Phila Pa 1976). 2007;32:249-55. doi: 10.1097/01.brs.0000251745.00674.08.

10. Jensen IB, Bergstrom G, Ljungquist T, Bodin L. A 3-year follow-up of a multidisciplinary rehabilitation programme for back and neck pain. Pain. 2005;115:273-83. doi:10.1016/j. pain.2005.03.005.

11. Marnetoft SU, Selander J. Long-term effects of early versus delayed vocational rehabilitation--a four-year follow-up. Disabil Rehabil. 2002;24:741-5. doi:10.1080/09638280210124338.

12. Marnetoft SU, Selander J, Bergroth A, Ekholm J. Vocational rehabilitation--early versus delayed. The effect of early vocational rehabilitation compared to delayed vocational rehabilitation among employed and unemployed, longterm sick-listed people. Int J Rehabil Res. 1999;22:161-70. doi:10.1097/00004356-199909000-00002.

13. Mellin G, Härkapää K, Hurri H, Järvikoski A. A controlled study on the outcome of inpatient and outpatient treatment of low back pain. Part IV. Long-term effects on physical measurements. Scand J Rehabil Med. 1990;22:189-94.

14. Mitchell RI, Carmen GM. The functional restoration approach to the treatment of chronic pain in patients with soft tissue and back injuries. Spine (Phila Pa 1976). 1994;19:633-42.
15. Taimela S, Takala EP, Asklof T, Seppälä K, Parviainen S. Active treatment of chronic neck pain: a prospective randomized intervention. Spine (Phila Pa 1976). 2000;25:1021-7.

16. van den Hout JH, Vlaeyen JW, Heuts PH, Zijlema JH, Wijnen JA. Secondary prevention of work-related disability in nonspecific low back pain: does problem-solving therapy help? A randomized clinical trial. Clin J Pain. 2003;19:87-96. doi:10.1097/00002508-200303000-00003.

17. Westman A, Linton SJ, Theorell T, Ohrvik J, Wahlen P, Leppert J. Quality of life and maintenance of improvements after early multimodal rehabilitation: a 5-year follow-up. Disabil Rehabil. 2006;28:437-46. doi:10.1080/09638280500192694.

18. Karjalainen K, Malmivaara A, van Tulder M, Roine R, Jauhiainen M, Hurri H, et al. Multidisciplinary rehabilitation for fibromyalgia and musculoskeletal pain in working age adults. Cochrane Database Syst Rev. 2000:CD001984. doi: 10.1002/14651858.CD001984.

19. Karjalainen K, Malmivaara A, van Tulder M, Roine R, Jauhiainen M, Hurri H, et al. Multidisciplinary biopsychosocial rehabilitation for neck and shoulder pain among working age adults. Cochrane Database Syst Rev. 2000:CD002194. doi: 10.1002/14651858.CD002194.

20. Karjalainen K, Malmivaara A, van Tulder M, Roine R, Jauhiainen M, Hurri H, et al. Multidisciplinary biopsychosocial rehabilitation for subacute low back pain among working age adults. Cochrane Database Syst Rev. 2003:CD002193. doi: 10.1002/14651858.CD002193.

21. The Social Insurance Institution of Finland (SII). Statistical yearbook of the Social Insurance Institution, Finland, 2009. Helsinki: SII 2010.

22. Arokoski JP, Juntunen M, Luikku J. Use of health-care services, work absenteeism, leisure-time physical activity, musculoskeletal symptoms and physical performance after vocationally oriented medical rehabilitation-description of the courses and a one-and-a-half-year follow-up study with farmers, loggers, police officers and hairdressers. Int J Rehabil Res. 2002;25:119-31. doi:10.1097/00004356-200206000-00005

23. Holopainen K, Nevala N, Kuronen P, Arokoski JP. Effects of vocationally oriented medical rehabilitation for aircraft maintenance personnel--a preliminary study of long-term effects with 5-year follow-up. J Occup Rehabil. 2004;14:23342. doi:10.1023/B:JOOR.0000047426.84072.18

24. Nevala-Puranen N. Reduction of farmers' postural load during occupationally oriented medical rehabilitation. Appl Ergon. 1995;26:411-5. doi:10.1016/0003-6870(95)00027-5

25. Väyrynen S, Könönen U. Short and long-term effects of a training programme on work postures in rehabilitees: a pilot study of loggers suffering from back troubles. Int J Ind Ergon. 1991;7:103-09. doi:10.1016/0169-8141(91)90041-J.

26. Helo T. Evaluation of the costs and effects of the SII Aslakrehabilitation. Helsinki: The Social Insurance Institution of Finland 2000.

27. Leino P, Kivekäs J, Hänninen K. Effects of work-oriented fitness courses in lumberjacks with low back pain. J Occup Rehabil. 1994;4:67-76. doi:10.1007/BF02110046. 
28. Nevala-Puranen N. Effects of occupationally-oriented rehabilitation on farmers' work techniques, musculoskeletal symptoms, and work ability. J Occup Rehabil. 1996;6:191200. doi:10.1007/BF02110755.

29. Suoyrjö H, Oksanen T, Hinkka K, Kivimäki M, Klaukka $\mathrm{T}$, Pentti J, et al. The effectiveness of vocationally oriented multidisciplinary intervention on sickness absence and early retirement among employees at risk: an observational study. Occup Environ Med. 2009;66:235-42. doi:10.1136/ oem.2007.038067.

30. Chamberlain MA, Fialka Moser V, Schüldt Ekholm K, et al. Vocational rehabilitation: an educational review. J Rehabil Med. 2009;41:856-69. doi:10.2340/16501977-0457.

31. Suoyrjö H, Hinkka K, Kivimaki M, Klaukka T, Pentti J, Vahtera J. Allocation of rehabilitation measures provided by the Social Insurance Institution in Finland: a register linkage study. J Rehabil Med. 2007;39:198-204. doi:10.2340/165019770035 .

32. Saltychev M, Laimi K, Oksanen T, Pentti J, Virtanen M, Kivimäki M, Vahtera J. Predictive factors of future participation in rehabilitation in the working population: the Finnish public sector study. J Rehabil Med. 2011 Apr;43(5):404-10. doi:10.2340/16501977-0788.

33. Rosenbaum PR, Rubin DB. The central role of the propensity score in observational studies for causal effects. Biometrika. 1983;70:41-55. doi:10.1093/biomet/70.1.41.

34. Shah BR, Laupacis A, Hux JE, Austin PC. Propensity score methods gave similar results to traditional regression modeling in observational studies: a systematic review. J Clin Epidemiol. 2005;58:550-9. doi:10.1016/j.jclinepi.2004.10.016.

35. Sturmer T, Joshi M, Glynn RJ, Avorn J, Rothman KJ, Schneeweiss S. A review of the application of propensity score methods yielded increasing use, advantages in specific settings, but not substantially different estimates compared with conventional multivariable methods. J Clin Epidemiol.
2006;59:437-47.

36. dBell S, Orr L. Screening (and creaming?) applicants to job training programs: the AFDC homemaker-home health aide demonstrations. Labour Econom. 2002;9:279-301. doi:10.1016/S0927-5371(02)00006-4.

37. Pearl J. Understanding propensity scores. In Causality: models, reasoning, and inference. Cambridge: Cambridge University Press 2009.

38. The world health report 2002: reducing risks, promoting healthy life. Geneva: World Health Organization, 2002.

39. OECD. Transforming disability into ability: policies to promote work and income security for disabled people. Paris: OECD Publication Service, 2003.

40. Stattin M, Jarvholm B. Occupation, work environment, and disability pension: a prospective study of construction workers. Scand J Public Health. 2005;33(2):84-90. doi:10.1080/14034940410019208.

41. OECD. OECD Employment Outlook 2008. Paris: OECD Publishing, 2008.

42. Statistical Yearbook of Pensioners in Finland Official Statistics of Finland 2009. Helsinki: Finnish Centre for Pensions and the Social Insurance Institution of Finland, 2010. Available from: http://www.etk.fi/Binary. aspx?Section=42845\&Item $=64965$. [Accessed 4 May 2011.]

43. Work and Pension Statistics 2004. Newcastle upon Tyne: Department for Work and Pensions, 2005. Available from: http://research.dwp.gov.uk/asd/asd1/workandpens/2004/ wps2004.pdf. [Accessed 4 May 2011.]

44. Annual Statistical Report on the Social Security Disability Insurance Program 2009. Washington DC: Social Security Administration Publication, 2010. Available from: http://www. socialsecurity.gov/policy/docs/statcomps/di_asr/2009/ di_asr09.pdf. [Accessed: 4 May 2011.]

Received for publication: 2 March 2011 